\title{
The First Decade of Biomedical Engineering Degree Program at the University of Malaya: Experiences and Achievements
}

\author{
N.A. Kadri1,2, M.G. Raha2, N.A. Abu Osman2 and W.A.B. Wan Abas2 \\ ${ }_{1}$ Centre of Biomedical Engineering, University of Surrey, Guildford, United Kingdom \\ 2 Department of Biomedical Engineering, Faculty of Engineering, University of Malaya, Kuala Lumpur, Malaysia \\ INTRODUCTION
}

The Department of Biomedical Engineering at the Faculty

of Engineering, University of Malaya, was first established

in the 1997/1998 academic session as a Programme

of Biomedical Engineering. It was administered by a Head

of Programme who is directly responsible to the Dean of the

Faculty.

The idea of establishing the programme was mooted

sometime in 1995 by a group of professors at the Faculty of

Engineering, namely W.A.B. Wan Abas, P. Raveendran,

and $\mathrm{M}$. Moghavvemi. At that time the local healthcare industry

requires graduates with a strong practical background

in basic engineering and biology, to fulfil the demand for

biomedical engineers. The increase in demand for experts in

such a niche area may partly be explained by the move of

the global healthcare industry towards evidence-based

medicine, coupled with the advancement in the areas of

bioinstrumentation and communications.

Based on several sets of undergraduate biomedical engineering

curricula and syllabi from selected universities

worldwide, the first Malaysian biomedical engineering

degree programme was created, with an emphasis on providing

basic mechanical, electronics, and electrical engineering

knowledge with an appreciation of human biological

system.

Program structure

The Biomedical Engineering degree programme was initially 
offered in the 1997/1998 academic session as a threeyear programme, with a Sijil Persekolahan Malaysia (SPM, equivalent to 'O'-Levels) or its equivalent entry requirement. This was changed to a four-year degree program starting from the 2000/2001 session with an SPM entry requirement. The entry requirement was later changed in the 2002/2003 session by only accepting students with a Sijil Tinggi Persekolahan Malaysia (STPM, equivalent to ALevels) or its equivalent. The changes in the entry requirements were in accordance to the various changes in directives received from the Ministry of Higher Education (MOHE).

The initial student intake was a modest 20 students in the 1997/1998 academic session; and the number has been increasing steadily with an intake projection of 100 students by the year 2010 . As of the $2003 / 2004$ session, there were 74 graduates produced by the Department. The Department has consistently ensure that $30 \%$ of the graduates has a Cumulative Grade Points Average (CGPA) of 3.0 (out of maximum 4.0).

The curriculum is revised and evaluated regularly, as per the directives from the MOHE, and was also approved by the Public Services Department, the Board of Engineers (BEM), and the Institute of Engineers, Malaysia (IEM). The curriculum consisted of $15 \%$ University courses and $85 \%$ Faculty and Departmental courses. The breadth of variety in the course topics ensured that the students receive a minimum of basic theoretical knowledge and the necessary technical skills within all disciplines in biomedical engineering to be able to solve practical problems independently.

The Programme initially had two interim professors assigned from other departments, five lecturers, and a small number of support staff members. This has since grown into 12 academic staff members, with a professor and two associate professors. The Department also has a sizeable number of support staff members and tutors in ensuring the Department 
is run as efficiently as possible.

In 2001, the Faculty of Engineering has decided to grant

the full Departmental status to the Programme of Biomedical

Engineering, with the then Head of Programme becoming

the new Head of Department. The year was also the

same year that the Programme produced its first batch of

graduates.

In 2002 the Faculty provided the Department with its own building, Block $A$, located near the entrance to the Faculty of Engineering (Fig. 1). Apart from the Departmental office, the building also housed four lecture rooms (maximum capacity of 80 students each), lecturer rooms, and several laboratories.

\section{ACHIEVEMENTS AND MILESTONES}

The following subsections provide a summary of milestones achieved by the Department between 1997 and 2008.

Note that the list is organised neither chronologically nor in order of importance.

\section{A. Accreditation by EAC}

As part of the national body responsible for accrediting the engineering undergraduate courses in the local higher learning institutes, the Engineering Accreditation Council (EAC) conducted a thorough evaluation process for all undergraduate engineering programmes in the country. The Department was visited three times by the EAC to evaluate the three different programme structures offered thus far and has been awarded a full accreditation for all of the programmes. The next EAC visit will be in 4 years' time and the Department should be more than ready to fulfil all of the criteria.

\section{B. Implementation of Outcome-Based Education}


Since 2005, the Department has prepared itself in embracing the Outcome-Based Education (OBE) implementation, which has been set as one of the criterion in the accreditation process by the EAC. Numerous workshops and discussion groups have been organised, including one that was handled by R.M. Felder and R. Brent, world-renown proponents in effective engineering education, in ensuring that all Departmental staff members and students are wellversed in its objectives and execution. This is particularly important as it involved noticeable changes in teaching, learning and assessment techniques.

All of the approved changes in the delivery of the programme were made in accordance to the Programme Eductional Objectives (PEO) and Programme Outcomes (PO). These were based on the aspiration to produce graduates whom are equipped with both the technical knowledge and the personal skills to survive in the global biomedical engineering industry.

The implementation of OBE at the Department may be described as successful, as the EAC has given its full accreditation to all undergraduate programmes offered by the Department thus far.

\section{Establishment of MSMBE}

The Department has been instrumental in the establishment of the Malaysian Society of Medical and Biological Engineering (MSMBE) in 2005. The idea of creating a unifying body of local biomedical engineering researchers and academics has been mooted for some time, and during the Biomed 2004 conference the MSMBE is born. A protem committee was also established with the main purpose of compiling all relevant documentation for the process of registering the society at the Malaysian Registrar of Societies. In the first MSMBE Annual General Meeting in 2006, the main office bearers were all members of the Department, namely the President (W.A.B. Wan Abas), the Secretary 
(N.A. Kadri), and the Treasurer (S.C. Ng). The majority of the committee members were also members of the Department.

At the World Congress on Medical Physics and Biomedical Engineering 2006 in Seoul, Korea, MSMBE was

officially announced as the sole representative of Malaysia under the IFMBE. The society has since participated in aorder of importance number of meetings and discussions organised by the IFMBE Working Group on Asia-Pacific Activities.

\section{Biomed conference series}

The Biomed conference series is a biennial event organised by the Department and was established in 2000, when it was first organised as a regional biomedical engineering conference. The inaugural international Biomed conference was held in 2002, and since then has received an increasing number of submitted papers and participants.

Over the years the conference series have received support from various sources, including the University of Malaya, IFMBE, International Union for Physical and Engineering Sciences in Medicine (IUPESM), the Malaysian Chapter of Institute of Electrical and Electronics Engineers (IEEE), National Heart Institute, IEM, Ministry of Health, and Tourism Malaysia. It has also been co-organised with Inje University, Korea and MSMBE. Financial support has always been welcoming, particularly from Healthtronics and other biomedical engineering companies in Malaysia. More importantly, the Biomed conference series has also received support from the Prime Minister's Office since 2004 (Fig. 2). This special relationship also led to the Office awarding the Department a special research grant amounting to RM 2 million.

Apart from the plenary and normal track sessions, there were also tutorial sessions on selected topics being conducted in each of the conferences. An official conference dinner is also organised for the delegates to savour the local delicacies while being entertained by colourful performances 
from the Tourism Malaysia.

\section{E. Collaboration with other universities}

The Department also has a number of fruitful collaborations with other universities, be it in terms of research or undergraduate education. Some of the collaborations are coordinated by the Faculty of Engineering, but a few is initiated and handled by the Department itself.

One of the more successful collaboration has been with the Inje University, Korea. A Memorandum of Understanding (MoU) has been signed between the two universities in 2006, with the Department being the principal representative of the University of Malaya in maintaining the relationship and keeping the collaborative efforts going. A number of activities have been agreed by both parties, including student and academic staff exchange program and joint research activities. Two batches of Inje University students from the Department of Biomedical Engineering and the Department of Biomedical Science have come to Malaysia to spend one semester at the University of Malaya in 2005 and 2006 (Fig. 3). A batch of 15 students from the University of Malaya had also spent one semester of their education at Inje University in 2007. Inje University is also the co-organiser of the Biomed 2006 conference.

A number of unofficial collaboration efforts have also been initiated with other local universities and abroad, including Auckland University of Technology, INSERM Lyon, National University of Singapore, Queen Mary University of London, University of California Irvine, University of Technology Compiegne, and University of WisconsinMadison.

Full text is available at :

http://link.springer.com/chapter/10.1007/978-3-540-69139-6_22 